\title{
Drug Informatics from Evolution to the Present Outlook
}

\author{
Minyahil A Woldu* and Jimma L Lenjissa
}

Ambo University, Department of Pharmacy, College of Medicine and Health Sciences, Clinical Pharmacy Unit, Ambo, Ethiopia

\begin{abstract}
Informatics is the science of information and the blending of people, biomedicine and technology. Medical informatics as a discipline is still young, in particular when compared to other medical disciplines. The American Medical Informatics Association defined medical informatics as "all aspects of understanding and promoting the effective organization, analysis, management, and use of information in health care". Drug informatics emphasizes the use of technology as an integral tool in effectively organizing, analyzing, and managing information on medication use in patients. Drug Informatics is a specialty area within the realm of clinical pharmacy that has evolved as technology and clinical practice have changed. The objective of this review is to make the reader familiar with the term, informatics, medical informatics and drug information; to describe the evolution of the informatics world; to describe the purpose, requirements and functions of drug information center (DIC). Effective drug information and evaluation skills are a vital part of routine pharmacy practice. Drug information specialists are trained individuals who have clinical knowledge and skills that allow them to provide clear, concise, and accurate recommendations regarding drug use. DIC is a unit designed for receiving, collecting, analyzing, and providing unbiased, accurate and up-to-date information about drugs and their use. Drug information Service (DIS) is the activities function and projects through which the DICs achieve their objectives and which constitute their programs of work. The Purposes of DIC include provision of comprehensive, meaningful and well evaluated information on drugs with a view to enhancing the rational use of drugs; disseminate technical, scientific \& objective information to health care providers; disseminate appropriate drug information to the general public; generate, collect, analyze and maintain drug information data; design produce and distribute drug information materials and give appropriate information on toxicology and poisoning. In conclusion, even though the discipline is still young and expected to be stronger in the future, the involvement of pharmacist as a drug information provider has been limited to specific areas of activities. Therefore, it is on the shoulder of the pharmacist to act appropriately and to change the outlook of the activities in near future.
\end{abstract}

Keywords: Drug informatics; Drug information; Medical informatics; Drug information Center; Function of drug information centers

\section{Introduction}

Informatics is the science of information and the blending of people, biomedicine and technology. Individuals who practice informatics are known as informaticians or informaticists [1]. Increasingly healthcare policy and decision makers are demanding evidence to justify investments in health information data [2] Data are symbols or observations reflecting differences in the world. Information is meaningful data or facts from which conclusions can be drawn by assessing the result. Knowledge is information that is justifiably considered to be true. Wisdom is the critical use of knowledge to make intelligent decisions and to work through situations of signal versus noise [3] (Figure 1). Drug information is a specialty area within the realm of clinical pharmacy that has evolved as technology and clinical practice have changed. Drug informatics and drug information can be used interchangeably [3].

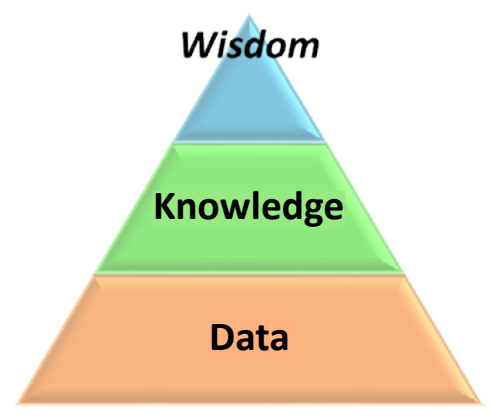

Figure 1: Information Hierarchy [1]

\section{Methods}

One hundred eighty articles were browsed from pubmed using the $\mathrm{MeSH}$ Browser, for items about Drug informatics, drug information, medical informatics and DIC and similarly articles were browsed using google search engine. Then, one hundred twenty eight of the articles were excluded due to lack of relevant information for the specific topic and the rest 52 articles were used to write this review article.

\section{Evolution of the Informatics World}

It is useful to look at the evolution of drug information practice from the perspective of drug information centers and of practicing pharmacists [4] The healthcare industry was facing major challenges: increasing costs, unacceptable error rates, and dissatisfied patients and providers [5]. Information technology has expanded to encompass nearly every industry in the world from finance and banking to Universities and nonprofits organizations [6], The U.S. Institute of Medicine (IOM) reported that "at least 44,000 and perhaps as many as 98,000 Americans die in hospitals each year as a result of medical errors". The numbers may not be exact, but the key point is that there is considerable loss of life due to medical errors that can be avoided if

*Corresponding author: Minyahil A Woldu, Department of Pharmacy, College of Medicine and Health Sciences, Ambo University, Ambo, Ethiopia P.O.Box: 19 Tel: +251912648527; E-mail: minwoldu@gmail.com

Received May 27, 2014; Accepted August 27, 2014; Published September 01 2014

Citation: Woldu MA, Lenjissa JL (2014) Drug Informatics from Evolution to the Present Outlook. J Health Med Informat 5: 161. doi:10.4172/2157-7420.1000161

Copyright: (c) 2014 Woldu MA, et al. This is an open-access article distributed under the terms of the Creative Commons Attribution License, which permits unrestricted use, distribution, and reproduction in any medium, provided the original author and source are credited. 
appropriate safety mechanisms are put in place [5].

Early applications of information technology in health care began in the 1960s with a focus on financial (eg, generating a bill) and clerical (eg, admission, discharge, and transfer transactions) systems [7,8]. With the introduction of powerful personal computers and networking technologies in the 1980s, the development of more clinically-oriented computer systems came for health care [7].

Medical informatics as a discipline is still young, in particular when compared to other medical disciplines [9]. Medical Informatics is a rapidly growing field that is concerned with applying computer science and information technology to medical and health data. The American Medical Informatics Association defined medical informatics as "all aspects of understanding and promoting the effective organization, analysis, management, and use of information in health care" [10] (Figure 2).

Informatics is more about using technology to help people do cognitive tasks better than about building systems to mimic or replace human expertise [11]. Drug informatics emphasizes the use of technology as an integral tool in effectively organizing, analyzing, and managing information on medication use in patients [4].

The central purpose of medical informatics is the dissemination of two core types of information: patient-specific information created in the care of patients and knowledge-based information, which includes the scientific literature of health care [12]. The promise of health information technology (HIT) for improving quality and safety of health care while reducing costs has caught the eye of policy makers and other leaders in health care [13].

The American Society of Health-System Pharmacists (ASHP) believes that pharmacists have the unique knowledge, expertise, and responsibility to assume a significant role in medical informatics [14]. Hence, the provision of medication information is among the most fundamental responsibilities of pharmacists. The information may be either patient specific, as an integral part of pharmaceutical care, or relative to a group of patients, such as in the development of a therapeutic guideline, publishing an electronic newsletter, or updating a website [15].

The responsibilities of individual pharmacists regarding the provision of medication information have changed substantially over the years. Impetus for this change was provided not only by the development of drug information centers and the clinical pharmacy concept, but also by the Study Commission on Pharmacy. This external

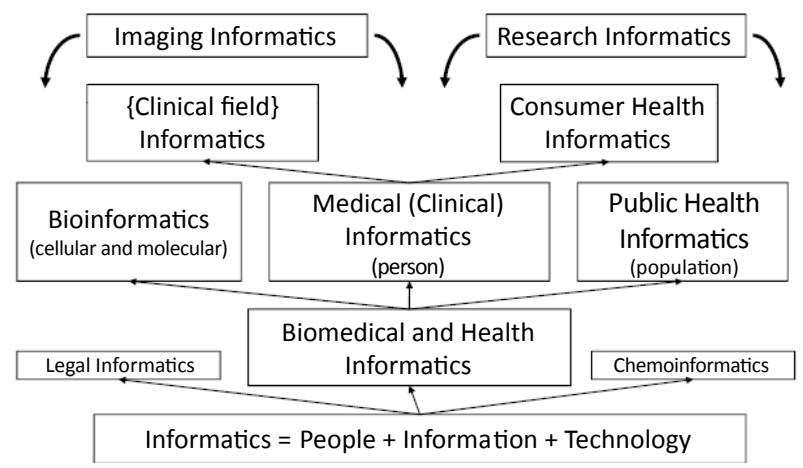

Figure 2: Major subcategories of the informatics field [13]

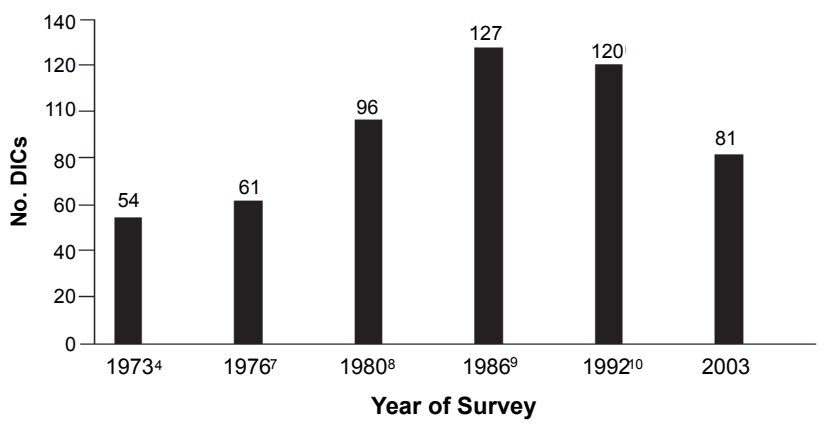

Figure 3: Number of Drug Information Centers (DICs) Meeting Listed Criteria Identified in Surveys, 1973-2003 [18]

group was established to review the state of the practice and education of pharmacists and report its findings [15].

\section{Drug Information Center}

Drug information Service (DIS) is the activities function and projects through which the Drug Information Centers (DICs) achieve their objectives and which constitute their programs of work. DIC is a unit designed for receiving, collecting, analyzing, and providing unbiased, accurate and up-to-date information about drugs and their use [16]. DICs have existed for more than 40 years, primarily affiliated with hospitals and/or colleges of pharmacy. Three general areas of responsibility exist: service, education and research. In the area of service, specific functions such as answering questions, supporting the Pharmacy and Therapeutics Committee, and preparing newsletters are frequent. Educational responsibilities often include teaching pharmacy students drug information skills. Evaluation of the services has focused mostly on answering questions and Pharmacy and Therapeutics (P\&T) Committee functions. Funding generally is provided by the institution with which the center is affiliated [17] (Figure 3).

DICs play a major role in providing reliable and updated information to health care professionals, especially if the centers' actions are independent from government and pharmaceutical industry. DICs must not only provide information of good quality but can also improve patient outcomes [19]. Since inappropriate use of medicines wastes resources and seriously undermines the quality of patient care. The WHO recognizes independent DIC as a core component of national programs to promote the rational use of drugs [20].

A DIC must be geared to the needs of its users. Information must be dependable, timely, and of the highest possible standard. The center's expertise should be readily accessible to all potential users [20].

\section{Purpose of Drug Information Center [16]}

$\checkmark$ To provide comprehensive, objective and evaluated information on drugs with a view to enhancing the rational use of drugs.

$\checkmark$ To disseminate technical, scientific \& objective information to health care providers.

$\checkmark$ To disseminate appropriate drug information to the general public

$\checkmark$ To generate, collect, analyze and maintain drug information data

$\checkmark$ To design produce and distribute drug information materials 
To give appropriate information on toxicology and poisoning

\section{Requirements for Drug Information Centers}

Rational use of drugs requires access to objective drug information [16]. The ever growing number of pharmaceuticals, the increased amount and complexity of literature, and the critical need for unbiased assessment of clinical data underscore the importance of well-developed DI skills [21]. DIC require clinically trained staff with access to specialist support. In some cases drug information services can be provided in conjunction with toxicology services and pharmacovigilance programs [20].

DICs should be organised on a cooperative model involving a multi-disciplinary team of professionals. Appropriate budget source, staff training facilities and service quality assurance mechanisms should be made available. Where possible, existing resources such as a libraries, computers, internet and databases should be used [20].

\section{Roles of the Drug Information Centers [22]}

$>$ Receiving, seeking, processing information and give feedback on drug information to regional and local centers, organizations, entities related to drug manufacturing, trading and using.

$>$ Setting up and updating a set of database (including information on medicines, drug interactions, adverse drug reactions, drug safety and effectiveness, drug use in particular cases...).

> Carrying Vertical Professional Instruction: supporting professional activities, monitoring and investigating drug information activities of regional and local centers.

$>$ Participating in composing, publishing professional documents related to drug information and pharmacovigilance.

$>$ Supporting under- and post graduate training and continuous training programmes.

$>$ Organizing and participating in scientific research, conferences, workshops, training courses on drug information abroad and in the country.

$>$ Organizing and participating in domestic and international projects on medicines; setting up and maintaining information exchange with international and regional drug information and pharmacovigilance networks.

$>$ Supplying guidelines for using information on demand of health professionals, enterprises and the public or to orders of other organizations and individuals

\section{Function of Drug Information Centers}

Responding to Drug Information Enquires: The primary function of a DIC is to respond to enquiries on therapeutic drug use [20]. The DIC shall answer drug related enquiries coming from health professionals and general public from any part of the country or the world [16]. Generally, a five-step systematic technique will be used for answering drug information requests. Step 1 is classification of the request. Step II involves determination of exactly what information is being requested and why, and ensuring that all pertinent background data are obtained. Step III is a systematic search of the literature, beginning with general references and progressing through secondary sources to primary articles. Step IV is formulation of the accumulated data into an appropriate written of verbal response. Step V involves reclassification of the request which may be necessary if there is a change in its scope [4,23] (discussed in detail in chapter three). Answers given to public enquiries should be handled in conjunction with treating physician and results should be followed up by the center [16] (Figures 1-3).

Therapeutic Advice: Many centers offer patient-related drug information as their primary activity. This requires an adequate understanding of disease states and therapy. It also requires access to appropriate resources for rapid support in situations where response time is an important factor in delivering optimum therapy. Therapeutic advice includes factors such as efficacy, optimum dosage, interactions, adverse effects, mode of administration, effects of other disease states, and strategies to promote adherence in chronic conditions [20].

Drugs and Therapeutics Committee (DTC) and Formulary Support: Drug and Therapeutics Committees (DTC) is a committee essential for ensuring the rational use of drugs in hospitals [24]. The DTC comprises a group of health professionals that advices on a health care provision on matters related to drug management [25].

A DTC can significantly improve drug use and reduce costs in hospitals and other health care facilities in the following ways (discussed in detail in chapter thirteen) $[20,25,26]$

$>$ providing advice on all aspects of drug management

$>$ developing drug policies

$>$ evaluating and selecting drugs for the formulary list

$>$ developing (or adapting) and implementing standard treatment guidelines

$>$ Prepares own list of drugs

$>$ assessing drug use to identify problems

$>$ conducting interventions to improve drug use

$>$ managing adverse drug reactions and medication errors

$>$ Informing all staff members about drug use issues, policies and decisions.

$>$ Decides on the classification of drugs as prescription or OTC on the basis of the national list on such categorization at Health institution level. And further categorizes which drugs should be prescribed by whom.

$>$ Designs and organizes educational programs regarding drugs and drug use.

$>$ Recommend additions and deletions from the list of drugs accepted for use in the health establishments

$>$ Facilitates the establishment of Drug information unit and assess its impact in the promotion of rational drug use.

$>$ Prepares annual plan of action and budget.

Dvaluates its annual performance

$>$ Gives recommendations concerning drugs to be stocked in health institution patient units or services.

$>$ Initiates and coordinates Studies on problems related to rational use of drugs, proper distribution and labelling of medications.

> Facilitates the Management of Medication Errors.

Drug Utilization Review: Drug Utilization Reviews (DUR), also 
referred to as Drug Utilization Evaluations (DUE) or Medication Utilization Evaluations (MUE), are defined as an authorized, structured, ongoing review of healthcare provider prescribing, pharmacist dispensing, and patient use of medication $[27,28]$ to assess drug therapy appropriateness and ensure patient safety [29]. It involve a comprehensive review of patients' prescription and medication data before, during, and after dispensing to ensure appropriate medication decision making and positive patient outcomes [27].

DUR has been a standard part of pharmacists' practice for many years [30]. DUR programs play a key role in helping managed health care systems understand, interpret, and improve the prescribing, administration, and use of medications [27].

Assessment of therapeutic drugs is an important function of a DIC. The center must have access to the principal medical and pharmaceutical journals. The staff should be capable of critically assessing the medical literature, and information from industry and media sources. Critical analysis of published research includes an interpretation of the results in terms of relevance to local practice [20].

DURs are classified into three categories [27]

$>$ Prospective-evaluation of a patient's therapy before medication is dispensed

$>$ Concurrent-ongoing monitoring of drug therapy during the course of treatment

Retrospective-review of therapy after the patient has received the medication

Adverse Drug Reaction (ADR) Reporting: Adverse Drug Reactions (ADRs) are any undesired or unintended effect of drug treatment. Drug treatment include both prescription and non-prescription medications; natural health products; biologically derived products such as vaccines and fractionated blood products; cells, tissues and organs; radiopharmaceuticals; and disinfectants and sanitizers with disinfectant claims [31].

ASHP defines a significant ADR as any unexpected, unintended, undesired, or excessive response to a drug that [32]

1) Requires discontinuing the drug (therapeutic or diagnostic),

2) Requires changing the drug therapy,

3) Requires modifying the dose (except for minor dosage adjustments)

4) Necessitates admission to a hospital,

5) Prolongs stay in a health care facility

6) Necessitates supportive treatment,

7) Significantly complicates diagnosis,

8) Negatively affects prognosis, or

9) Results in temporary or permanent harm, disability, or death.

Prescription medications are responsible for up to 7000 American deaths per year, with the cost of drug-related morbidity and mortality being nearly U.S. $\$ 77$ billion per year. The definition of adverse drug events (ADEs) includes both medication errors and ADRs [4] Reactions may occur under normal use conditions of the product. Reactions may be evident within minutes or years after exposure to the product and may range from minor reactions like a skin rash to serious and life-threatening events such as a heart attack or liver damage [31] (Table 1).

\section{Patient Counselling}

Patient counselling is defined as providing medication information orally or in written form to the patients or their representative or providing proper directions of use, advice on side effects, storage, diet and life style modifications [34]. Information through counselling is essential for patients to assist in adhering to their medication regimens [35]. It involves a one-to-one interaction between a pharmacist and a patient and/or a care giver. It is interactive in nature. The effective counselling should encompass all the parameters to make the patient/ party understand his/her disease [34]. Pharmacy is expected by the public as the place where they find reliable health and medicines information and the pharmacist as the most qualified provider of such services [36]. Pharmacist's communication skills therefore needs to be further developed into a more patient cantered approach in order to take greater account of patient's perspectives and experiences in using their medication [37] (Table 2).

\section{Pharmaceutical Advice}

Most other enquiries will relate to pharmaceutical preparations generally and include issues of availability, formulation, cost, storage and stability [20].

\section{Continuing Education Programs}

Educational activities are important to support the quality use of drugs. Providing information to health professionals and the public is part of continuing health education. A DIC can also support national and regional authorities responsible for drug use programs. Training graduate and undergraduate students is an important aspect of overall clinical training. Healthcare practitioners need to understand the scope and functions of DICs in order to utilise the services they offer [20].

DIC then shall provide education on drugs to the target audience (health professionals and consumers) using/through mass media and educational materials. It shall also provide education on how to improve rational prescribing and dispensing practices and the use of individual drugs of categories of drugs, organize trainings and continuing education programmers on drug information, to health professionals [16].

\section{Investigational Drug Studies}

Pharmacists traditionally have been involved in clinical trial research in a variety of ways, from providing drug and record keeping for drug accountability to taking on the roles from study coordinator to principal investigator [38]. Today, pharmacists are on the forefront of patient care and do make a significant impact on the health status of patients' directly through pharmaceutical care and indirectly by connecting patients to pharmaceutical treatments through the practice of Evidence Based Medicine with existing treatments or with participation in clinical trials. As medication experts, pharmacists are educated to develop the skills to solve medication related problems and improve patient outcomes with their interventions [39].

ASHP believes pharmacists should play a pivotal role in the management of drugs used in the conduct of clinical research. Pharmacists have become essential components of health system infrastructures supporting clinical research with both approved drugs and investigational drugs [40-42]. 
Citation: Woldu MA, Lenjissa JL (2014) Drug Informatics from Evolution to the Present Outlook. J Health Med Informat 5: 161. doi:10.4172/21577420.1000161

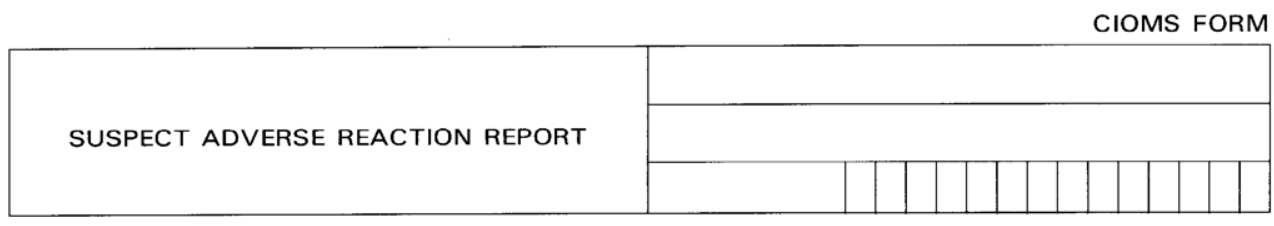

I. REACTION INFORMATION

\begin{tabular}{|c|c|c|c|c|c|c|c|c|c|c|}
\hline \multirow{2}{*}{$\begin{array}{l}\text { 1. PATIENT INITIALS } \\
\text { (first, last) }\end{array}$} & \multirow[t]{2}{*}{ 1a. COUNTRY } & \multicolumn{3}{|c|}{ 2. DATE OF BIRTH } & \multirow{2}{*}{$\begin{array}{l}\text { 2a. AGE } \\
\text { Years }\end{array}$} & \multirow[t]{2}{*}{ 3. SEX } & \multicolumn{3}{|c|}{ 4-6 REACTION ONSET } & \multirow{2}{*}{$\begin{array}{c}\text { 8-12 CHECK ALL } \\
\text { APPROPRIATE } \\
\text { TO ADVERSE } \\
\text { REACTION }\end{array}$} \\
\hline & & Day & Month & Year & & & Day & Month & Year & \\
\hline \multirow{4}{*}{\multicolumn{10}{|c|}{$7+13$ DESCRIBE REACTION(S) (including relevant tests/lab data) }} & $\square$ PATIENT DIED \\
\hline & & & & & & & & & & $\begin{array}{l}\text { INVOLVED OR } \\
\text { PROLONGED } \\
\text { INPATIENT } \\
\text { HOSPITALISATION }\end{array}$ \\
\hline & & & & & & & & & & $\begin{array}{l}\square \text { INVOLVED } \\
\text { PERSISTENCE OR } \\
\text { SIGNIFICANT } \\
\text { DISABILITY OR } \\
\text { INCAPACITY }\end{array}$ \\
\hline & & & & & & & & & & $\begin{array}{l}\square \text { LIFE } \\
\text { THREATENING }\end{array}$ \\
\hline
\end{tabular}

II. SUSPECT DRUG(S) INFORMATION

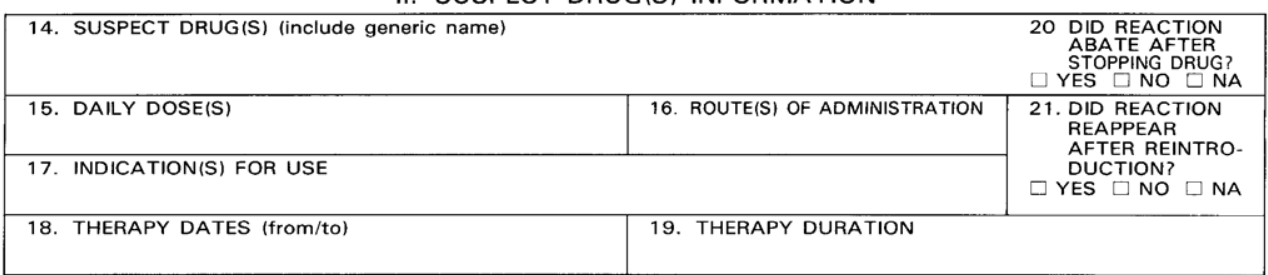

III. CONCOMITANT DRUG(S) AND HISTORY

\begin{tabular}{|l|}
\hline 22. CONCOMITANT DRUG(S) AND DATES OF ADMINISTRATION (exclude those used to treat reaction) \\
\hline 23. OTHER RELEVANT HISTORY (e.g. diagnostics, allergics, pregnancy with last month of period, etc.) \\
\hline
\end{tabular}

IV. MANUFACTURER INFORMATION

\begin{tabular}{|l|c|}
\hline 24a. NAME AND ADDRESS OF MANUFACTURER \\
\hline & 24b. MFR CONTROL NO. \\
\hline $\begin{array}{l}\text { 24c. DATE RECEIVED } \\
\text { BY MANUFACTURER }\end{array}$ & $\begin{array}{c}\text { 24d. REPORT SOURCE } \\
\square \text { STUDY } \square \text { LITERATURE } \\
\square \text { HEALTH PROFESSIONAL }\end{array}$ \\
\hline DATE OF THIS REPORT & $\begin{array}{c}\text { 25a. REPORT TYPE } \\
\text { INITIAL } \square \text { FOLLOWUP }\end{array}$ \\
\hline
\end{tabular}

Table 1: Council for International Organizations of Medical Sciences (CIOMS) ADR reporting Form [33].

\section{Main responsibilities for clinical drug trials investigator}

[43]

$>$ Reviews protocols for clinical investigational drug trials, as required.

> Liaises with principal investigators and/or trial coordinators/ research assistants to establish pharmacy's role, determine fee schedules and to implement dispensing, compounding and billing procedures.

$>$ Communicates with, and trains staff anticipated to participate in any aspect of the clinical investigational drug trial.

> Maintains a pharmacy binder which contains a study summary, protocol, dispensing procedures, completed samples of required paperwork, dispensing checklist, fee schedule, billing procedures and any other relevant materials for each investigational trial.

$>$ Maintains and coordinates distribution of an up-to-date clinical investigational drug trials list, as scheduled.

$>$ Maintains responsibility for the management of the inventory for clinical investigational drug trials; orders, replaces and returns study materials, as required.

$>$ Communicates any concerns regarding ethical issues or deviation from established policies \& procedures.

$>$ Assists in ensuring the participation of the pharmacy department in all clinical trials which involve drugs. 
Citation: Woldu MA, Lenjissa JL (2014) Drug Informatics from Evolution to the Present Outlook. J Health Med Informat 5: 161. doi:10.4172/21577420.1000161

\begin{tabular}{|c|c|c|c|c|}
\hline \multirow[b]{2}{*}{ Activity } & \multicolumn{4}{|c|}{ Mean \% of Time ${ }^{a}$} \\
\hline & $\begin{array}{c}1980 \\
(n=78)^{8}\end{array}$ & $\begin{array}{c}1986 \\
(n=121)^{9}\end{array}$ & $\begin{array}{c}1992 \\
(n=115)^{10}\end{array}$ & $\begin{array}{c}2003 \\
(n=68)\end{array}$ \\
\hline $\begin{array}{l}\text { Answering drug information } \\
\text { requests }\end{array}$ & 57.0 & 37.2 & 30.2 & 34.7 \\
\hline $\begin{array}{l}\text { Participating on pharmacy and } \\
\text { therapeutics committee }\end{array}$ & $\ldots \mathrm{b}$ & 12.9 & 11.2 & 13.8 \\
\hline Providing training or education & & 7.6 & 9.2 & 13.4 \\
\hline $\begin{array}{l}\text { Producing newsletters } \\
\text { Reporting adverse drug }\end{array}$ & 11.0 & 7.5 & 5.3 & 5.7 \\
\hline $\begin{array}{l}\text { reactions } \\
\text { Performing administrative }\end{array}$ & $\cdots$ & 1.8 & 6.0 & 5.5 \\
\hline duties (not related to DIC) & ... & 6.3 & 5.7 & 4.9 \\
\hline Conducting drug-use reviews & & 4.7 & 5.8 & 4.4 \\
\hline $\begin{array}{l}\text { Conducting literature searches } \\
\text { Giving lectures and }\end{array}$ & 12.0 & 6.7 & 4.8 & 4.4 \\
\hline presentations & 9.0 & 5.7 & 3.6 & 3.6 \\
\hline Conducting inservice education & $\ldots$ & $\ldots$ & 2.0 & 1.9 \\
\hline Reviewing patients' therapy & $\ldots$ & 1.8 & 2.0 & 1.2 \\
\hline Reviewing articles for journals & $\ldots$ & $\ldots$ & 0.6 & 1.1 \\
\hline Counseling patients & $\ldots$ & 0.7 & 1.0 & 1.0 \\
\hline Preparing review articles & 4.0 & 2.0 & 0.6 & 0.9 \\
\hline Preparing columns for journals & 3.0 & 0.7 & 1.0 & 0.8 \\
\hline Providing abstracting services & 2.0 & 0.7 & 4.5 & 0.6 \\
\hline $\begin{array}{l}\text { Conducting admission or } \\
\text { discharge interviews }\end{array}$ & $\ldots$ & 0.3 & 0.2 & 0.2 \\
\hline Other ${ }^{c}$ & 2.0 & 3.1 & 2.0 & 2.5 \\
\hline
\end{tabular}

Table 2: Percentage of Time Spent on Drug Information Center (DIC) Activities [18].

\section{Research}

DICs should be involved in research activities including pharmacoepidemiology, e.g. drug utilisation studies and pharmacovigilance. The nature of enquiries received can be used to plan educational programs within the center or provided to organisations responsible for improving the quality of drug use. Specialist centers should also assess the quality and relevance of commonly used information resources [20]. The research can be conducted by the DIC itself or in collaboration with others and then the needs in drug information and the design and value of drug information materials will be periodically assessed [16].

\section{Drug Information Education}

The information provided should not be conflicting between the needs of the audience and legal or public health consideration. The information provided should not violate the relationship between the Prescriber/Dispenser and the patient. Rather it should strengthen the relationship between the two. The center shall not give information on chemical entities whose therapeutic merits are not yet provided and not released to the market for public consumption Shall provide drug information for medico-legal cases. The center shall provide independent information and without advertising a particular product for commercial purposes. The center shall provide reliable, accurate, up-to-date information in sustainable manner, which should be supported by references/literatures [16].

The following activities, which are often performed in an organized health care setting, are enhanced by using a systematic approach to meeting medication information needs [44-48]

1. Providing medication information to patients and families, health care professionals, and other personnel.

2. Establishing and maintaining a formulary based on scientific evidence of efficacy and safety, cost, and patient perceptions and outcomes.

3. Developing and participating in efforts to prevent medication misadventuring, including adverse drug event and medication error reporting and analysis programs.

4. Developing methods of changing patient and provider behaviours to support optimal medication use.

5. Publishing newsletters to educate patients, families, and health care professionals on medication use.

6. Educating providers about medication-related policies and procedures.

7. Coordinating programs to support population based medication practices (e.g., development of medication-use evaluation criteria and pharmacotherapeutic guidelines).

8. Coordinating investigational drug services.

9. Providing continuing-education services to the health care professional staff.

10. Educating pharmacy students and residents.

11. Applying health economic and outcome analysis. 
12. Developing and maintaining an active research program.

\section{Dissemination of Information}

DICs can disseminate information in the form of drug monographs, bulletins and websites. Editorial skills are important for these functions. The International Society of Drug Bulletins (ISDB) runs training courses for editors and, together with WHO, is preparing a manual for developing independent drug bulletins [21].

\section{Drug Information clients by category [16]}

- Health professionals

- Researcher

- Regulatory body

- General public

\section{Drug Information Category [16]}

- General product information

- Therapeutic efficacy

- Pharmaceutical Information

- Indication

- Side effects/Adverse effects

- Contraindication

- Drug interaction

- Toxicology

- Drug dosing (both adult, child)

- Special precautions

- Drug use in childhood, pregnancy, lactation, old age, and disease conditions

- Rational drug use

- Drug supply management

\section{The Impact of Clinical Pharmacy in Drug Information Centers}

The development of DICs and drug information specialists was the beginning of the clinical pharmacy concept. It laid the groundwork for pharmacists to demonstrate the ability to assume more responsibility in providing input on patient drug therapy. Pharmacists were provided the opportunity to extend their patient care contribution by taking a more active role in the clinical aspects of the decision-making process as it related to medication therapy [4].

Health care cannot be adequately provided without medicines and a competent pharmacy workforce to supply them. All over the world efforts are being made to change the scope of hospital pharmacy by moving the hospital pharmacists from dispensing counters into the wards and clinics [49]. Impetus for this change was provided not only by the development of DICs and the clinical pharmacy concept, but also by the Study Commission on Pharmacy [4]. As a discipline clinical Pharmacy is a health science in which pharmacists provide patient care that optimizes medication therapy and promotes health, wellness, and disease prevention. Clinical pharmacy also has an obligation to contribute to the generation of new knowledge that advances health and quality of life [50]. Pharmacists therefore could offer their expertise as consultants on medication therapy [4].

\section{Requirements for Drug Information Personnel}

Effective drug information and evaluation skills are a vital part of routine pharmacy practice. DI specialists are trained individuals who have clinical knowledge and skills that allow them to provide clear, concise, and accurate recommendations regarding drug use [3]. Effective DI and evaluation skills are a vital part of routine pharmacy practice [51].

The number of personnel required will depend on the range of activities offered and the hours of service. A DIC should aim to provide a direct service during periods of major demand by its clients. For patient-related enquiries this is likely to be when clinic consultations occur and during peak periods for hospital functions. The professional staff should include a full-time clinical pharmacist or a clinical pharmacologist. Clinical training and experience is essential for effective communication with clinicians. Other important attributes are computer skills, literature analysis, and editing and library management [20].

In addition to clinical knowledge and experience, drug information practitioners require [20]: Communication skills to receive and comprehend enquiries; Knowledge of all available resources;

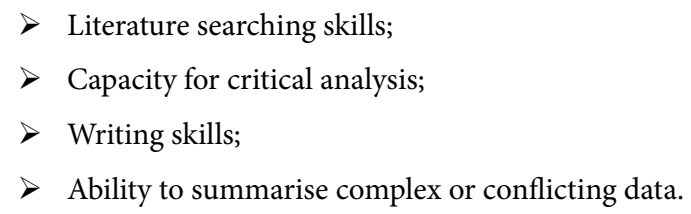

\section{Conclusion}

Even though the Drug informatics as a discipline is still young and expected to be stronger in the future, the involvement of pharmacists as a drug information provider has been limited to specific areas of activities. Therefore, it is on the shoulder of the new generation pharmacists to act appropriately and to change the outlook of the activities in near future.

\section{References}

1. Robert E. Hoyt, Elmer V. Bernstam (2011) Overview of Health Informatics.

2. Kushniruk AW, Patel VL (2004) Cognitive and usability engineering methods for the evaluation of clinical information systems. J Biomed Inform 37: 56-76.

3. Bernknopf AC, McKeever AL, Peak AS, Smith KM, Smith WD, et al. (2009) Drug information: from education to practice. Pharmacotherapy 29: 331-346.

4. Patrick M. Malone, Karen L. Kier, John E. Stanovich (2007) Drug Information: A Guide for Pharmacists: The McGraw-Hill Companies.

5. $7263 \mathrm{~N}(2005)$ Healthcare Strategic Focus Area: Clinical Informatics.

6. Siau K (2003) Health Care Informatics. IEEE Transactions on Information Technology in Biomedicine 7.

7. Debbie Travers, Larry Mandelkehr (2008) The Emerging Field of Informatics N C Med J 69

8. Center. VUM (2005) What is biomedical informatics?

9. Reinhold Haux ( $\left.\begin{array}{llll}2 & 0 & 1 & 0\end{array}\right)$ Medical informatics: Past, present, future. Int J Med Inform 79: 599-610.

10. Association AMI.

11. Friedman C (2009) A 'fundamental theorem' of biomedical informatics. J Am Med Inform Assoc 16: 169-170

12. Hersh WR (2002) Medical informatics: improving health care through information. JAMA 288: 1955-1958. 
Citation: Woldu MA, Lenjissa JL (2014) Drug Informatics from Evolution to the Present Outlook. J Health Med Informat 5: 161. doi:10.4172/21577420.1000161

13. Hersh W (2009) A stimulus to define informatics and health information technology. BMC Medical Informatics and Decision Making 9: 24.

14. Pharmacists ASoH-S (2007) ASHP Statement on the Pharmacist's Role in Informatics. pp. 12-15.

15. Malone PM, Kier KL, Stanovich JE, Drug Information: A Guide for Pharmacists MacGraw-Hill's.

16. DACA (2005) Guideline For The Establishment and Operation Of A DIC

17. Amerson AB (1986) Drug information centers: an overview. Drug Inf J 20: 173178.

18. Rosenberg JM, Koumis T, Nathan J P, Cicero A, Mcguire H (2004) Current status of pharmacist-operated drug information centers in the United States. Am J Health Syst Pharm 61: 2023-2032.

19. Fischer Lat MI, Pizzol TDSD (2012) User's Satisfaction in a Brazilian Drug Information Center: Evaluation under a New Approach. Latin American Journal of Pharmacy 31.

20. FPI S (2005) Requirements for Drug Information Centres.

21. I M, Lat F, TD S, Pizzol D (2012) User's Satisfaction in a Brazilian Drug Information Center: Evaluation under a New Approach. Latin American Journal of pharmacy 31.

22. Hanoi University of Pharmacy (2009) The National Centre of Drug Information and Adverse Drug Reactions Monitoring.

23. Watanabe AS, McCart G, Shimomura S, S. K (1975) Systematic approach to drug information requests. Am J Hosp Pharm 32: 1282-1285.

24. Vang C, Tomson G, Kounnavong S, Southammavong T, Phanyanouvong A, et al. (2006) Improving the performance of Drug and Therapeutics Committees in hospitals--a quasi-experimental study in Laos. Eur J Clin Pharmacol 62: 57-63.

25. DACA (2004) Working guidelines for the establishment and operation of drug therapeutics committee.

26. Health WIcwMSf (2003) Drug and therapeutics committees: A practical guide. Geneva, Switzerland: WHO.

27. Robert Navarro (2008) Drug Utilization Review Strategies. Academy of Managed Care Pharmacy. pp. 215-229.

28. Pharmacists ASoH-S (1996) ASHP Guidelines on Medication-Use Evaluation. pp. 1953-1955

29. JE T (2009) A Practical Guide to Contemporary Pharmacy Practice. Philadelphia: LippincottWilliams \& Wilkins.

30. Hennessy S, Strom BL, Lipton HL, SB. S (2000) Drug utilization review. In: Strom BL, editor. Pharmacoepidemiology. 3rd ed: John Wiley \& Sons Ltd.

31. Canada H (2011) Adverse Reaction Reporting and Health Product Safety Information Guide for Health Professionals.

32. Pharmacists ASoH-S (1995) Guidelines on Adverse Drug Reaction Monitoring and Reporting. Am J Health-Syst Pharm 52: 417-419.

33. CIOMS (2014) ADR reporting form.

34. Palaian S, Prabhu M, Ravi Shankar P (2006) Patient Counseling by Pharmacist -A Focus on Chronic Illness. Pak J Pharm Sci 19: 62-65.

35. BBe (2005) Communication skills for pharmacist: Building relationships, improving patient care. Washington DC: American Pharmaceutical Association.

36. Puspitasari HP, Faturrohmah AAH (2011) Do Indonesian community pharmacy workers respond to antibiotics requests appropriately? . Trop Med Int Health 16: $840-846$

37. Rathan SM, Jyothi D, Durga Prasad TS, Venkata Subbaiah M, Ravindra Reddy $\mathrm{K}$, et al. (2013) Role of clinical pharmacist in impact of patient counselling in asthmatic patients. Journal of Global Trends in Pharmaceutical Sciences 4: 1111-1117.
38. Rockwell K, Bockheim-McGee C, Jones E KI (1999) Clinical research: National survey of US pharmacy-based investigational drug services-1997. Am J Health-Syst Pharm 56: 337-344.

39. Oncology CPGi (2006) Prostate Cancer. National Comprehensive Cancer Network.

40. Stolar MH, Gabriel T, Grant KL, Koeller J, Letendre DE (1982) Pharmacycoordinated investigational drug services. Am J Hosp Pharma 39: 232-236.

41. Pharmacists ASoH-S (1995) ASHP guidelines: minimum standard for pharmacies in hospitals. Am J Health-Syst Pharm 52: 2711-2717.

42. Pharmacists ASoH (1992) ASHP statement on the use of medications for unlabeled uses. Am J Hosp Pharm 49: 2006-2008.

43. Network TUH (2010) Pharmacist, Clinical Trials Job description.

44. Rosenberg JM, Ruentes RJ, Starr CH, Kirschenbaum HL, McGuire H, et al (1995) Pharmacist operated drug information centers in the United States. Am J Health Syst-Pharm 52: 991-999.

45. Practice Assalofrtidi (1994) American Society of Hospital Pharmacists. Practice standards of ASHP Bethesda: Hicks WE.

46. Pharmacists ASoH (1992) ASHP accreditation standard for residency in pharmacy practice (with an emphasis on pharmaceutical care). Am J Hosp Pharm 49: 146-153.

47. Pharmacists ASoH (1989) ASHP statement on the pharmacist's clinical role in organized health care setting. Am J Hosp Pharm 46: 2345-2346.

48. Pharmacists ASoH-S (1996) ASHP Guidelines on the Provision of Medication Information by Pharmacists. Am J HealthSyst Pharm 53: 1843-1845.

49. Nousheen Aslam KZA (2011) Clinical Pharmacy Clerkship in Pakistan: A leap from paper to practice INNOVATIONS in pharmacy.

50. Pharmacotherapy (2008) The Definition of Clinical Pharmacy 28: 816-817.

51. Fei Wang, Williams GT, Rosenberg JM (2006) Drug Information Education in Doctor of Pharmacy Programs. Am Journal Pharm Educ 70: 51 